\title{
Alguns apontamentos sobre o Acordo Ortográfico: três olhares lusófonos - Brasil, Moçambique e Portugal ${ }^{1}$
}

\author{
Some notes about the Orthographic Accord: \\ three Lusophone opinions - Brazil, \\ Mozambique and Portugal
}

\author{
Nilce da SILVA \\ Domingos Carlos BUQUE \\ Luís Miguel CARDOSO \\ Maria de Jesus FONSECA
}

\section{RESUMO}

Este artigo apresenta um breve histórico dos diferentes acordos ortográficos da Língua Portuguesa que foram feitos ao longo da história. Em seguida, por meio de três olhares - português, moçambicano e brasileiro discutem-se algumas questões decorrentes do mais recente acordo da comunidade lusófona. Finalmente, os autores apresentam um elenco de questões importantes no âmbito dos países que têm a Língua Portuguesa como oficial e que não estão representadas nas questões possíveis de serem tratadas no contex to específico de um acordo ortográfico.

Palavras-chave: acordo ortográfico - Brasil, Portugal, Moçambique, Língua Portuguesa.

\begin{abstract}
This article presents a historical briefing of the different orthographic agreements that have been undertaken throughout History, pertaining to the Portuguese Language. Then, bearing on three points of view - Portuguese, Mozambiquean and Brazilian some questions will be discussed, which arise from the most recent agreement made within the lusophone community. Finally, the authors present a set of questions holding importance for the countries that have Portuguese as its official language which are not represented in the questions liable to be dealt within the context of an orthographic agreement.
\end{abstract}

Index Terms: orthographic agreement: Brazil, Portugal, Mozambique, Portuguese Language.

\footnotetext{
${ }^{1}$ Este artigo está sendo publicado na íntegra na Revista Millenium do mês de Abril, com o título: "Notícia(s) do Acordo Ortográfico da Língua Portuguesa. Três olhares lusófonos: Brasil, Moçambique e Portugal".
} 


\section{RÈSUMÈ}

Cet article présente, dans un premier temps, un bref historique des différents accords orthographiques qui ont été réalisés tout au long de l'histoire de la Langue Portugaise. Ensuite, à la vue des regards qui suivent, le portugais, le mozambicain et le brésilien, on discute- quelques questions relatives au plus récent accord fait par la communauté lusophone Pour conclure, les auteurs posent plusieurs questions essentielles dans le cadre de chaque pays qui ont comme langue officielle la langue portugaise, questions qui ne sont pas considérées comme étant possibles d'être traitées dans le contexte spécifique d'un accord d'orthographique.

Mots clés: accord orthographique : Brésil, Portugal, Mozambique; Langue Portugaise.

\section{Nota Prévia: versão com a ortografia de Portugal, anterior ao acordo}

Já este artigo estava escrito e dado como acabado, quando os meios de comunicação social portugueses publicitam a notícia de que o governo português aprovou, em Conselho de Ministros de 6 de março de 2008, véspera da partida do Presidente da República², Aníbal Cavaco Silva, para a visita ao Brasil, a convite do Presidente brasileiro Lula da Silva, no âmbito das comemorações dos 200 anos da chegada ao Brasil da corte de D. João VI, uma "Proposta de Resolução que aprova o Acordo do Segundo Protocolo Modificativo ao Acordo Ortográfico da Língua Portuguesa, adoptado na V Conferência dos Chefes de Estado e de Governo da Comunidade dos Países de Língua Portuguesa (CPLP), realizada em S. Tomé, a 26 e 27 de julho de 2004". ${ }^{3}$ Esclarece-se, ainda, no portal do governo, que

[...] esta resolução, a submeter à aprovação da Assembleia da República, refere-se ao Protocolo Modificativo que vem alterar o Acordo Ortográfico da Língua Portuguesa, cujo processo interno de aprovação foi concluído por Portugal em 1991. A alteração diz respeito à disposição relativa à entrada em vigor do Acordo e vai no sentido de a mesma ocorrer com o depósito do terceiro instrumento da ratificação dos Estados contratantes, como é prática nos acordos da CPLP, e não, como previsto anteriormente, após depositados os instrumentos de ratificação por todos os Estados.

\footnotetext{
${ }^{2}$ Disponível em: <http://www.presidencia.pt/brasil2008/?idc=158\&idi=14156>. Acesso em:12 mar. 2008.

${ }^{3}$ Disponível em: <http://www.portugal.gov.pt/Portal/PT/Governos/Governos_Constitucionais/GC17/Conselho_ de_Ministros/Comunicados_e_Conferencias_de_Imprensa/20080306.htm>. Acesso em: 12 mar. 2008.
} 
O Acordo do Segundo Protocolo Modificativo ao Acordo Ortográfico da Língua Portuguesa, que se visa aprovar, com esta proposta de resolução, vem, ainda, permitir a adesão da República Democrática de Timor-Leste ao Acordo Ortográfico da Língua Portuguesa.

O Estado português adoptará as medidas adequadas a garantir o necessário processo de transição, no prazo de 6 anos, nomeadamente ao nível da validade da ortografia constante dos actos, normas, orientações ou documentos provenientes de entidades públicas, bem como de bens culturais, incluindo manuais escolares, com valor oficial ou legalmente sujeitos a reconhecimento, validação ou certificação.

O ministro da Cultura, José António Pinto Ribeiro, que integrava a comitiva presidencial na visita ao Brasil, segundo uma notícia publicada no Semanário Expresso de 8 de março de 2008, referia que a aplicação do Acordo Ortográfico "não ficará sujeita a moratória, como defendia a sua antecessora Isabel Pires de Lima, mas apenas a um prazo de seis anos para que o acordo seja aplicado em toda a sua plenitude" ${ }^{4}$ No semanário Sol, também de 8 de março de 2008, lia-se que

[...] após três adiamentos em Conselho de Ministros, foi finalmente ratificado o novo Acordo Ortográfico. (...) A decisão, que estava iminente desde o final de 2007, foi tomada no momento em que o Presidente da República e o ministro da Cultura estão em visita oficial ao Brasil. ao Sol ter

Silvas Filho, da Sociedade Portuguesa da Língua Portuguesa, disse $[\ldots]$ a impressão de que tudo se precipitou por causa da
ida do Presidente Cavaco Silva ao Brasil. Com certeza que ti-
nha de levar alguma coisa "para oferecer" e levou isto. Mas ti-
nha de acontecer, mais cedo ou mais tarde, sob o risco de fi-
carmos isolados. Assim temos uma língua portuguesa planetá-
ria, digamos, uma língua de oito pátrias.

Foi neste contexto que nos pareceu muito actual a publicação deste artigo. Como escreveu, quase premonitoriamente diríamos, José Eduardo Agualusa num artigo publicado no semanário angolano $A$ capital, de 9 de fevereiro de $2008^{6}$, intitulado “Acorda Acordo ou dorme para sempre!" Enfim, o Acordo acordou, depois de dormir durante quase duas décadas, res-

\footnotetext{
${ }^{4}$ Disponível em: <http://www.ciberduvudas.pt/noticias.php?rid=1623>. Acesso em: 12 mar. 2008.

${ }^{5}$ Disponível em: <http://www.ciberduvidas.pt/noticias.php?rid=1624>. Acesso em: 12 mar. 2008.

${ }^{6}$ Disponível em: <http://www.ciberduvidas.pt/controversias.php?rid=1602>. Acesso em: 12 mar. 2008.
} 
suscitando, finalmente, de um sono comático e do estado de total entorpecimento em que se encontrava. O beijo do príncipe quebrou o feitiço e salvou a Bela Adormecida do sono eterno! Mesmo em tempo!

Acresce que na origem deste artigo esteve presente a ideia de o escrever a várias mãos. Aconteceu ser escrito a quatro mãos, ou, se quisermos ser mais precisos, a oito mãos. De facto, os seus autores são quatro, um brasileiro, outro moçambicano e dois portugueses, tendo-se procurado no texto reflectir diferentes olhares de diferentes países lusófonos sobre o assunto. Depois de termos o artigo já pronto, lembrou-se a Nilce de nos desafiar, com ironia: "Então e se usássemos as novas normas ortográficas do acordo para escrever o nosso texto?”

Num primeiro momento, assustámo-nos com esta ousadia e ficámos confusos. Não, não devíamos usar as novas regras ortográficas previstas no acordo, porque, tanto quanto sabíamos naquela altura, de facto o acordo está ratificado por alguns países, mas não entrou ainda em vigor; assim, se não está em vigor, por que fazê-lo? Por que ousar? Por que arriscar? Mas, logo de seguida, pensámos: "contudo, por outro lado, até seria divertido e mesmo interessante (inovador?) escrevê-lo usando a ortografia do Acordo.” E, imediatamente, outra ideia surgiu: "então e se apresentarmos o texto nas duas versões para os leitores compararem?” E assim se fez. Tomada esta decisão, o risco de cometermos alguns erros ortográficos é real. Esperamos, por isso, compreensão e benevolência, porque, como referiu ao semanário Sol, Mário Mendão, consultor jurídico da CPLP, importa "desdramatizar":

Não estamos a falar e uma polícia dos erros ortográficos. Ninguém vai multar uma pessoa por escrever mal as palavras. A ideia é as novas regras irem-se instituindo aos poucos, à medida que vamos usando, e, com isso, treinando a nova ortografia. (Sol, 8 mar. 2008)

Mas as novidades ainda não tinham acabado de nos surpreender. Entretanto, visitando páginas Web de editoras portuguesas e sites

\footnotetext{
${ }^{7}$ Disponível em: <http://www.ciberduvidas.pt/noticias.php?rid=1624>. Acesso em: 12 mar. 2008.
} 
correlacionados, deparamo-nos com a notícia de terem acabado de ser lançadas no mercado português as seguintes publicações, já de acordo e em conformidade com o Acordo Ortográfico: dois Dicionários, o Novo Dicionário de Língua Portuguesa e o Novo Grande Dicionário de Língua Portuguesa, e ainda um livro, Atual - O Novo Acordo Ortográfico. ${ }^{8}$ Vão, com certeza, constituir uma grande ajuda para que possamos navegar na nova grafia da Língua Portuguesa, como é nosso intento, com maior à vontade e segurança.

\section{Introdução}

Este artigo trata do Acordo Ortográfico, da "Última flor do Lácio, inculta e bela", de 1990, a partir de três olhares, envolvendo pesquisadores e professores do Brasil, Moçambique e Portugal. Ou seja, é resultado da história iniciada pelo período conhecido como "Grandes Navegações", começo da colonização portuguesa e da disseminação da língua e cultura lusitanas:

Era o povo português que sem o saber, estava fazendo mais do que sua história, estava escrevendo a própria história da humanidade. E tudo isto, sessenta anos antes de qualquer outra nação pensar em abalar-se para o mar [...] só o puderam fazer porque já existia toda uma ciência náutica portuguesa, desenvolvida como a astronomia e a navegação, nessa Universidade do mar que foi a Escola de Sagres [...] (COSTA, 1988, p. 14).

Nesta época, conforme o mesmo estudioso, dos 300.00 homens que compunham a população economicamente ativa de Portugal, 30.000 eram marinheiros que colaboraram fortemente para a presença de Portugal como metrópole em diferentes continentes, de forma que podemos falar da existência de um Império Português, como sabemos, o mais duradouro deles de 1415, com a tomada de Ceuta, a 1999, com a entrega de Macau para a República Popular da China. Vários são os nomes nestas Grandes Viagens:

\footnotetext{
${ }^{8}$ Disponível em: <http://www.mediabooks.pt/index.jsp>. Acesso em: 12 mar. 2008. Disponível em: <http://tex toeditora.mediabooks.pt/artigos/todas_novidades_s.jsp?v_id=9>. Acesso em: 12 mar. 2008.
} 
Diogo Cão, Bartolomeu Dias, Vasco da Gama, Pedro Álvares Cabral, dentre outros. Além de Portugal, hoje, apenas os seguintes países têm a língua portuguesa como oficial: Angola, Cabo Verde, Guiné-Bissau, Moçambique, Brasil, São Tomé e Príncipe e Timor-Leste.

Levando-se em consideração esses dados — a quantidade de territórios conquistados em todas as regiões do globo terrestre e a longevidade da colonização portuguesa é impossível, no âmbito deste artigo, percorrermos esta história. E mais do que a referida dimensão, temos que levar em consideração o quão pouco sabemos acerca da história de Portugal e de suas excolônias.

Apesar, e talvez por isso, da imensa fraqueza em termos da consolidação do mundo da lusofonia, 1911 a 2008 — período de 97 anos, a língua portuguesa terá sofrido quatro reformas ortográficas. Questionamos: Como, em tão pouco tempo - em se falando de línguas que gozam de respaldo e oficialidade - muda-se tão profundamente a grafia de uma língua, a golpes de decretos, SOBRETUDO quando faladas em comunidades linguísticas visivelmente em transição?

Em países em que os cidadãos, em sua quase totalidade, não são $l e i$ turizados, qual a real necessidade de uma unificação da língua portuguesa? As nações falantes teriam, com a reforma, um instrumento político que se reverteria em seu benefício, ou somente os contratos entre esses países não mais necessitariam de "tradução" e nem de adequação, como já ouvimos defensores desta unificação usarem como argumento fundamental?

Para tentarmos compreender estas questões, vejamos a seguir a cronologia e a história das diferentes reformas e acordos que modificaram a ortografia da Língua Portuguesa. 


\section{Acordo(s) ortográfico(s) da Língua Portuguesa}

\subsection{Cronologias, história e histórias}

A intenção de estabelecer uma grafia comum, uma ortografia unificada, válida para todos os países de língua oficial portuguesa, é a intenção que preside, desde sempre, aos sucessivos ensaios e esforços tendentes ao estabelecimento de um Acordo Ortográfico da Língua Portuguesa, que vigore em todos os países de Língua oficial portuguesa, não só nos Países Africanos de Língua Oficial Portuguesa (Palop), mas em todos os países que constituem a CPLP ${ }^{9}$.

Por outro lado, trata-se também de acordar uma escrita mais simples, uma norma ortográfica simplificada, mais próxima da fonética e, portanto, mais próxima da pronúncia e do português falado.

De facto, actualmente, não há uma única norma ortográfica para o mundo lusófono, mas sim duas: uma norma própria no Brasil, outra em Portugal, esta última comum aos restantes países que constituem os Palop, também membros da CPLP: Angola, Moçambique, Cabo Verde, Guiné-Bissau e São Tomé e Príncipe. Timor Leste tornou-se o oitavo membro da CPLP mais recentemente, em 20 de maio de 2002, após a sua independência.

Assim, o Português torna-se a única língua viva do mundo que apresenta e usa mais que uma ortografia oficial. Possui mais de 230 milhões de

\footnotetext{
${ }^{9}$ O processo de criação da CPLP iniciou-se em novembro de 1989, em São Luís do Maranhão, no primeiro encontro de Chefes de Estado e de Governo dos sete países de Língua Portuguesa, realizado a convite de José Sarney. Deste mesmo encontro saiu a ideia da criação do Instituto Internacional da Língua Portuguesa (IILP). No entanto, só 7 anos mais tarde, em Lisboa, a 17 de julho de 1996, formalmente se cria a CPLP. O IILP, contudo, só viria a tornar-se realidade em 2004. Na Declaração constitutiva da CPLP pode ler-se que a Comunidade "considera imperativo e reitera (...) a afirmação e divulgação cada vez maiores da Língua Portuguesa como uma necessidade." Reafirmam que a Língua Portuguesa: "Constitui (...) um vínculo histórico e um património comum; É um meio privilegiado de difusão e criação cultural entre os povos que falam português e de projecção internacional dos seus valores culturais (...)", pretendendo, por isso, "incentivar a difusão e enriquecimento da Língua Portuguesa, potenciando as instituições já criadas ou a criar com esse propósito, nomeadamente o Instituto Internacional da Língua Portuguesa (IIPL)”. Disponível em: <http://www.cplp.org/> e <http://www.iilp-cplp.cv/>.
} 
falantes ${ }^{10}$, é a quinta língua mais falada no mundo inteiro, a terceira mais falada no mundo ocidental e língua oficial da Comunidade Europeia (CE).

A modificação deste estado de coisas é o objectivo subjacente aos esforços de se chegar a um Acordo Ortográfico que estabeleça uma ortografia comum e unificada para a Língua Portuguesa, de forma que a Língua Portuguesa escrita seja uniformemente usada em e por todos os países de Língua Oficial Portuguesa, através da adopção de uma norma ortográfica comum.

A implantação da República, em 5 de outubro de 1910, em Portugal, permitiu a primeira reforma ortográfica da Língua Portuguesa. Passou-se de uma escrita baseada na raiz etimológica das palavras, defendida pelos gramáticos, para uma escrita mais simplificada e mais consentânea com a fonética e com a pronúncia da língua falada.

Contudo, esta primeira reforma, oficializada por Portaria de 1 de setembro de 1911, a ser usada nas publicações oficiais e no ensino, transformou radicalmente o aspecto da língua escrita, assemelhando-a à grafia actual, mas aplicou-se apenas em Portugal e foi levada a cabo sem sequer se buscar qualquer acordo com o Brasil, então o único país independente, porquanto os restantes, à altura, eram ainda colónias portuguesas. Assim, esta reforma aplicou-se apenas em Portugal mas não no Brasil.

Só em 1924 a Academia de Ciências de Lisboa e a Academia Brasileira de Letras deram início aos trabalhos tendentes a estabelecer uma ortografia comum. Em $1931^{11}$, um primeiro acordo adoptava a ortografia imposta pela reforma de 1911, mas mantinham-se ainda divergências gráficas.

\footnotetext{
${ }^{10}$ Segundo os dados constantes na "Declaração constitutiva da Comunidade dos Países de Língua Portuguesa" e na página Web oficial da CPLP, no endereço <http://www.cplp.org/>, bem como no link para os "estados membros".São ainda membros associados da CPLP, como observadores, a Guiné Equatorial e a República da Ilha Maurícia. Disponível em: 〈http://www.cplp.org/quemsomos_obsA.asp>.

${ }^{11}$ Em Portugal aprovado pela Portaria n. ${ }^{\circ} 7.117$, de 27 de maio de 1931. No Brasil, pelos Decretos n. ${ }^{\circ}$ 20.108 e 20.028 , de 15 de junho de 1931 e de 2 de agosto de 1933, respectivamente, e ainda pelo decreto-lei n. ${ }^{\circ} 292$, de 23 de fevereiro de 1938.
} 
Em 1940, a Academia de Ciências de Lisboa publica o Vocabulário Ortográfico da Língua Portuguesa, que veio a ser aprovado, em 1942, pela Academia Brasileira de Letras. Entretanto, a Academia Brasileira de Letras publica também o seu Vocabulário Ortográfico, concluído em 1943. Entre os dois Vocabulários havia ainda divergências significativas que importava ultrapassar, a fim de "completar a obra da unidade universal da língua portuguesa, que há vinte e dois anos as duas Academias vinham laboriosamente consolidando e estabilizando" $"$.

É assim que, em 1943, se realiza em Lisboa uma Convenção que levou ao Acordo Ortográfico de 1945. Este acordo, contudo, foi publicado em Portugal em $1945^{13}$, mas não entrou em vigor no Brasil, onde não foi ratificado.

Um Acordo firmado entre Portugal e o Brasil, em 1971, suprimiu acentos gráficos, os quais, por si só, representavam uma grande maioria das diferenças ortográficas entre os dois países. No Brasil, estas alterações foram determinadas pela publicação da Lei n. ${ }^{\circ} 5765$, de 18 de dezembro de 1971. Em Portugal, a introdução destas alterações ortográficas faz-se pelo Decreto-Lei n. ${ }^{\circ} 32 / 73$ de 6 de fevereiro, consignando o seu artigo único que "são eliminados da ortografia oficial portuguesa os acentos circunflexos e os acentos graves com que se assinalam as sílabas subtónicas dos vocábulos derivados com o sufixo mente e com os sufixos iniciados por z", podendo ler-se na sua introdução que o uso de tais acentos "chegava a ser responsável por cerca de $70 \%$ das divergências entre as duas ortografias oficiais".

As duas Academias, Portuguesa e Brasileira, reiniciaram contactos em 1973, tendo chegado de novo a acordo em 1975. Desta vez, tal acordo não chegou a ser aprovado oficialmente, devido, sobretudo, à situação política que se vivia em Portugal.

\footnotetext{
${ }^{12}$ Preâmbulo do Decreto n. ${ }^{\circ} 35.228$ de 8 de dezembro de 1945. Disponível em: <http://www.flip.pt> e <http://www.portaldalinguaportuguesa.org/?action=acordo\&version=1945=acordo-historia>. Acesso em: 24 jan. 2008).

${ }^{13}$ Decreto n. $^{\text {3 } 35.228}$, de 8 de dezembro de 1945.
} 
Realizou-se uma nova reunião no Rio de Janeiro em 1986, promovida pelo então Presidente do Brasil, José Sarney, onde estiveram presentes os representantes de Angola, Moçambique, Cabo Verde, Guiné-Bissau, São Tomé e Príncipe, do Brasil e de Portugal, de onde resultou um acordo que, contudo, nunca chegou a ser implementado.

Em 16 de dezembro de 1990 — já lá vão 17 anos — é assinado, em Lisboa, novo Acordo Ortográfico ${ }^{14}$, subscrito por todos os sete países de língua oficial portuguesa, e desta vez também com "a adesão da delegação de observadores da Galiza". Este acordo veio a ser aprovado e ratificado, em Portugal, pela Assembleia da República, em 4 de junho de 1991, e publicado, pela Resolução da Assembleia da República n. ${ }^{\circ}$ 26/91, em Diário da República, n. ${ }^{\circ}$ 193, I série A, em 23 de agosto de 1991, prevendo-se, no seu artigo $3^{\circ}$, a sua entrada em vigor a 1 de janeiro de 1994 , após ratificação de todos os Estados signatários. Contudo, só Portugal, o Brasil e Cabo Verde ratificaram este acordo, pelo que a sua entrada em vigor ficou, em consequência, adiada, muito embora conste na introdução deste diploma que o presente acordo "constitui um passo importante para a defesa da unidade essencial da língua portuguesa e para o seu prestígio internacional."

Permitimo-nos salientar que este Acordo Ortográfico de 1990 consubstancia um alfabeto, já não de 23, mas sim de 26 letras para a língua portuguesa, tendo-se introduzido as letras $\mathrm{K}, \mathrm{W}$ e $\mathrm{Y}$, por várias ordens de razões, entre as quais, "porque nos países africanos de língua oficial portuguesa existem muitas palavras que se escrevem com aquelas letras" ${ }^{15}$. Também suprime e elimina as consoantes mudas, bem como certos acentos, altera as regras do uso do hífen e, no Brasil, abole o trema.

Em 17 de julho de 1998, na cidade da Praia, em Cabo Verde, foi assinado um Protocolo modificativo ao Acordo Ortográfico, de onde se retirou

\footnotetext{
${ }^{14}$ Disponível em: <http://pt.wikipedia.org/wiki/Acordo_Ortogr\%C3\%A1fico_de_1990>. Acesso em: 24 jan. 2007.

${ }^{15}$ Resolução da Assembleia da República n. ${ }^{\circ}$ 26/91, de 23 de agosto. Cf. Ponto 7 do Anexo II - Nota Explicativa do Acordo Ortográfico da Língua Portuguesa.
} 
a data da sua entrada em vigor, continuando, contudo, a manter-se a necessidade da sua ratificação por todos os estados membros signatários para que o mesmo possa entrar em vigor. Também este protocolo foi ratificado apenas por Portugal, pelo Brasil e por Cabo Verde.

Em $2004^{16}$, os países membros da CPLP, reunidos em Fortaleza a 26 de maio, e, posteriormente, em S. Tomé e Príncipe, em 26 e 27 de julho, aprovam um $2^{\circ}$ protocolo modificativo, onde, para "além de permitir a adesão de Timor Leste" ao Acordo Ortográfico, se "define a entrada em vigor do Acordo com o depósito dos instrumentos de ratificação por três países signatários", abandonando-se a exigência de ratificação por todos os estados membros, da qual se fazia depender, até esta data, a entrada em vigor do Acordo. O Brasil em 2004, Cabo Verde em 2005 e S. Tomé e Príncipe em 2006 ratificaram o Acordo e os dois protocolos modificativos. Contudo, Portugal não ratificou este segundo protocolo modificativo.

O Acordo Ortográfico de 1990 previa “a elaboração, até 1 de janeiro de 1993, de um vocabulário ortográfico comum da Língua Portuguesa, tão completo quanto desejável e tão normalizador quanto possível, no que se refere às terminologias científicas e técnicas." $" 17$

Este Vocabulário, a elaborar pela Academia Brasileira de Letras e pela Academia de Ciências de Lisboa, precederia a entrada em vigor das normas constantes no Acordo Ortográfico. Por isso, no texto da sua publicação em Portugal, se referia que só entraria em vigor em 1994. O Vocabulário deveria fixar a grafia válida para todos os povos da lusofonia, acautelando duplas entradas para os casos de dupla grafia, atendendo, sobretudo, à pronúncia, deliberando sobre a adopção de neologismos e sobre o aportuguesamento de palavras estrangeiras, para além, é claro, das terminologias científicas e técnicas.

\footnotetext{
${ }^{16}$ Em 2002, na IV Conferência de Chefes de Estado e de Governo, a República Democrática de Timor Leste aderiu à CPLP, tornando-se o seu oitavo membro.

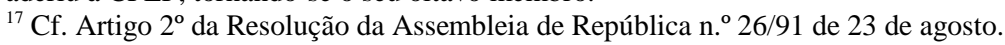


Tal Vocabulário não está ainda concluído, embora a Academia Brasileira de Letras tenha já publicado uma obra com 350 mil entradas, em 1998, e a Academia de Ciências de Lisboa tenha publicado um Dicionário com 70 mil entradas, em 2001.

O Acordo Ortográfico de 1990, no Brasil, passa a aplicar-se no presente ano de $2008^{18}$. Em Portugal, ainda não se sabe ${ }^{19}$, porque sobre o assunto tudo se vai dizendo, mas de concreto nada se diz oficialmente e reina a confusão ${ }^{20}$.

\footnotetext{
${ }^{18}$ Disponível em: <http://tools.folha.com.br/print?site=emcimadahora\&url=http://www1.folha.uol.com.br/ folha/educacao/ ult305u321371.shtml>, <http://leonardof.org/2007/08710/acordo-ortografico-da-linguaportuguesa/pt/>, <http://orto.blogs.sapo.pt/arquivo/1065449.html>, 〈http://ww1.rtp.pt/noticias/index.php? artcle $=30542 \&$ visual=26>; http://pt.wikipedia.org/wiki/Acordo_Ortogr\%C3\%A1fico_de_1990\#Posi.

C3.A7.C3.A3o_de_Portugal $>$. Acesso em: 24 jan. 2008).

19 "Não existe nenhuma notícia sobre a agenda do Governo português para a ratificação do acordo ortográfico da Língua Portuguesa. Pelo contrário, reina o mais completo silêncio." <http://causanossa.blogspot.com> e <http://causa-nossa.blogspot.com/2007/03/silncio.html>. Acesso em 29 jan. 2008. "Portugal é o país que mais hesita a introdução do Acordo. A comunicação social portuguesa dá pouco valor a esse assunto, como o Governo português, apesar dos vários encontros entre este e o governo brasileiro e das pressões de Lula da Silva e da Academia Brasileira de Letras. Apesar dos jornais brasileiros já terem adiantado que 2008 seria o ano da entrada em vigor do Acordo no Brasil, em Portugal não há uma data ainda definida." <http://pt.wikipedia.org/wiki/Acordo_Ortogr\%C3\%A1fico_de_1990\# Posi.C3.A7 C3.A3o_de_Portugal;>. Acesso em 24 jan. 2008.

${ }^{20}$ A imprensa, tanto a portuguesa como a brasileira, noticiava, no final do ano de 2007, informações tão díspares quanto as que se seguem: "No passado dia 02 de Novembro, o ministro dos Negócios Estrangeiros português, Luís Amado, anunciou que Portugal aprovaria o Protocolo Modificativo do Acordo Ortográfico de Língua Portuguesa até ao final deste ano." "A fonte confirmou que o processo de aprovação do documento, inicialmente previsto para o último conselho de ministros deste ano, a realizar quinta-feira, dia 27 , foi adiado para 2008, escusando-se a precisar a nova data." <http://ww1.rtp.pt/noticias/?article= 316142\&visual=26\&tema=5>. Acesso em 29 jan. 2008. Cf. <http://www.agencialusa.com.br/ index. php?iden=11364>, 〈http://www.agencialusa.com.br/index.php?iden=5233>, e <http://www.agencia lusa. com/br/index.php?iden=11364>. Acesso em 29 jan. 2008. "Por seu lado, a ministra da Cultura, Isabel Pires de Lima, anunciou a 27 de novembro, na Assembleia da República, que Portugal iria pedir um prazo de dez anos para a entrada em vigor do novo Acordo Ortográfico, que unifica a escrita da Língua Portuguesa." Disponível em: <http://ww1.rtp.pt/noticias/?article=316142\&visual=26\&tema=5>. Acesso em 29 jan. 2008. "Relativamente aos 10 anos de moratória para a entrada em vigor do Acordo Ortográfico que Portugal vai pedir - como há dias anunciou a ministra da Cultura, Isabel Pires de Lima, na Assembleia da República". Disponível em: 〈http://ww1.rtp.pt/noticias/index.php?article=307769\&visual=26\&tema=5>. Acesso em: 24 jan. 2008. Na wikipédia, a enciclopédia livre, pode ler-se que "Portugal ainda não ratificou o segundo protocolo modificativo, nem há ainda qualquer data para que isso aconteça. E, quando o fizer, segundo algumas fontes, poderá ainda introduzir uma 'cláusula de reserva diferindo a sua entrada em vigor na ordem jurídica interna'. Na prática, as novas normas já poderiam ter entrado em vigor nos três países que cumpriram todos os requisitos. Mas considera-se inviável que o acordo vá adiante sem que Portugal também dê por concluído todo o processo." Disponível em: <http://pt.wikipedia.org/wiki/Acordo_Ortogr\%C3\%A1fico_de_1990\#His torial_do_processo>. Acesso em: 24 jan. 2008. Cf. ainda <http://www.agencialusa.com.br/index.php?iden= 5278>. Acesso em: 24 jan. 2008.
} 
Seja como for, a aplicação destas normas implicará alteração na grafia de cerca de $1,6 \%$ do vocabulário usado em Portugal e de 0,5\% no Brasil. ${ }^{21}$ Vejamos a seguir algumas questões colocadas por este "novo" acordo.

\section{Algumas questões colocadas pelo Acordo}

Sobre o Acordo Ortográfico e sua aplicação, muito se tem dito e escrito. Defendendo-se as mais variadas posições, desde o radicalismo extremista da rejeição de uns, à atitude mais moderada e ponderada de outros, que analisam criticamente e pesam prós e contras, avaliam vantagens e desvantagens, e ajuízam, concordando e defendendo o Acordo, sobretudo, considerando o inegável interesse político e cultural de uma escrita unificada. As vozes que se erguem no debate sobre o Acordo Ortográfico estão incluídas num espectro que varia entre os apoiantes, os cépticos e os críticos. Apesar de inúmeras personalidades terem já apresentado publicamente a sua concordância genérica com as vantagens - políticas e educacionais —, de uma uniformização a Comunicação Social tem feito eco de posições díspares que revelam momentos de cisão ou de hesitação. Recorde-se que, no início dos anos de 1990, o Acordo Ortográfico sofreu uma contestação muito acesa, levando, inclusivamente, à elaboração de um "Movimento contra o Acordo Ortográfico", que reuniu personalidades dos mundos universitário, político e empresarial.

Em Portugal, a atitude mais conservadora ${ }^{22}$, que parece ser a atitude dominante, é a de rejeição, que se traduz na oposição e recusa pura e simples do Acordo, muitas vezes acrítica, quase sempre sem fundamento, outras vezes revelando apenas ignorância, desconhecimento sobre o Acordo ${ }^{23}$, por vezes mesmo alguma estupidez.

\footnotetext{
${ }^{21}$ Disponível em: <http://www.agencialusa.com.br/index.php?iden=9483>. Acesso em: 29 jan. 2008.

${ }^{22}$ É a atitude do Velho do Restelo, tão bem retratada por Camões e tão característica do povo português. Ou, como diz Silvas Filho, "Os defensores do caduco 'orgulhosamente sós que se cuidem..."”. Disponível em: <http://www.ciberduvidas.pt/controversias.php?rid=1517>.

${ }^{23}$ Disponível em: <http://orto.no.sapo.pt/c00.htm>. Acesso em: 24 jan. 2008.
} 
Outros negam a utilidade do Acordo, afirmando que não é sequer necessário, porque as diferenças gráficas não impedem a inteligibilidade e compreensão dos textos escritos. Para outros, ainda, a reforma ortográfica que o Acordo propõe é tímida, não é sequer suficientemente arrojada, uma vez que permite que muitos vocábulos continuem a escrever-se de forma diferente, como é o caso, por exemplo, de facto e fato, mantendo-se a dupla grafia para palavras que têm efectivamente pronúncia diferente em Portugal e no Brasil.

Apontam-se inconvenientes e prejuízos, principalmente os custos económicos e financeiros, face à necessidade de produção editorial de novos dicionários, gramáticas, livros didácticos e escolares e/ou literários, que terão de substituir os antigos, agora deitados no lixo, adoptando as novas normas ortográficas unificadas. Mas hoje qualquer documento oficial é redigido em duplicado: um com a grafia de Portugal, também luso-africana, e outro com a do Brasil.

Outros vêem na aplicação do Acordo a possibilidade de fortalecimento da Língua Portuguesa, pelo menos no médio prazo, a possibilidade da sua maior difusão e dignificação e, portanto, do seu prestígio. A existência de uma ortografia unificada, que possibilita a edição de livros comuns, de programas e acções comuns e conjuntas de formação, de cooperação educacional, e, nesta perspectiva, seguindo as editoras as mesmas normas ortográficas, consideram que há vantagens, inclusive económicas e financeiras. Padronizar a escrita da Língua Portuguesa é reclamar a unidade e universalidade dessa língua que é património e legado comum a todos os países lusófonos, património esse que será tanto mais comum, quanto mais comum for a sua ortografia.

O principal defensor do Acordo Ortográfico é Malaca Casteleiro, linguista, professor universitário, membro da Academia de Ciências de Lisboa, director do seu Instituto de Lexicologia e Lexicografia da Língua Portuguesa e um dos responsáveis pelo processo desde 1986. Malaca Casteleiro 
opina que o acordo de 1990 é realista, evidenciando a unificação possível da ortografia, permitindo uma melhor memorização dos casos de dupla ortografia ou acentuação. A simplificação é, aliás, a principal virtude deste acordo. Quanto ao ensino e aprendizagem do Português no estrangeiro, por exemplo, ou na utilização da língua em instituições internacionais, Malaca Casteleiro não hesita em demonstrar as virtudes deste entendimento que unifica a ortografia e permite uma maior projecção em termos internacionais. Seguindo o princípio da pronúncia em detrimento do critério etimológico, facilita-se a aprendizagem, virtude que Agualusa também defende, nomeadamente tendo em mente a questão da alfabetização nos países africanos. Analisando as causas da não-implementação do acordo, Malaca Casteleiro relembra que não existiu verdadeiramente uma vontade explícita dos políticos portugueses em avançar com este caminho, devido, nomeadamente, às mudanças de governo em Portugal que acarretam novas directrizes no plano estratégico. Este linguista observa ainda que vários países lusófonos também tiveram momentos difíceis na sua situação política recente, como Angola, Moçambique e mesmo a Guiné-Bissau, facto que motivou o adiamento do debate sobre o Acordo Ortográfico.

Já Francisco José Viegas ${ }^{24}$, escritor e director da Casa Fernando Pessoa, considera que Portugal não pode deixar de integrar o processo, notando que a falta de atenção a esta problemática tem sido prejudicial, principalmente em termos editoriais, pelo que o atraso português deve ser ultrapassado em definitivo.

Recentemente, Carlos Reis, reitor da Universidade Aberta, publicou um $\operatorname{artigo~}^{25}$ sobre este tema e salientou desde logo que esta discussão, há cerca de dez anos, suscitou um nacionalismo muito forte e uma nítida falta de visão estratégica, resultando no argumento repetido e reiterado que se iria começar a "Falar como os brasileiros", ignorando os pessimistas que o a-

\footnotetext{
${ }^{24}$ Francisco José Viegas demitiu-se no dia 1 de fevereiro. A nova directora é a escritora Inês Pedrosa.

25 "Falar como os brasileiros", publicado na revista Visão, de 13 de dezembro de 2007.
} 
cordo não iria trazer consequências fonológicas nem sintácticas relevantes. Carlos Reis, consciente da possibilidade de ressurgimento dessas mesmas vozes que vêem a língua portuguesa como um património exclusivamente português, fruto de uma visão marcada pela clausura e pelo conservadorismo, lembra as vantagens de unir esforços com o Brasil, evitando-se o aprofundamento das divergências. Assim, uma unificação revelar-se-ia benéfica para a afirmação internacional da Língua Portuguesa. Argumenta inclusivamente, à luz dos pensamentos mais negativos, que, em teoria, também deveriam ser retirados das escolas gramáticas, dicionários e prontuários, porque estes se opõem naturalmente ao dinamismo e à inovação, possuindo, assim, a missão de zelar pela manutenção do idioma. No fundo, um acordo é um instrumento regulador como os citados instrumentos linguísticos, apresentando, consequentemente, as mesmas virtudes.

Com relação a Moçambique, temos que a década de 1990 foi rica em acontecimentos ligados à comunidade lusófona: primeiro foi a assinatura do Acordo Ortográfico em 1991 e depois, em 1996, foi a integração de Moçambique na Comunidade dos Países de Língua Portuguesa (CPLP). Estes dois eventos alimentaram discussões acaloradas, sobretudo entre académicos. Os mais radicais, recorrendo à localização geográfica do país, colocavam a hipótese de Moçambique retirar-se da CPLP e passar a fazer parte da Commonwealth, minimizando, por isso, a necessidade do Acordo Ortográfico, uma posição partilhada por políticos como, por exemplo, Joaquim Chissano, quando ainda timoneiro do país, conforme o excerto que se segue: "Moçambique está inserido numa região de países da Comunidade Britânica e por isso assistimos a muitas reuniões, o que fazemos com muito agrado porque temos um relacionamento económico com esses países, do qual não podemos fugir. Se houver elegibilidade, nós não temos problemas em aderir à Comunidade Britânica" 26

\footnotetext{
${ }^{26}$ Disponível em: <http://www.plcs.uma〉. Acesso em:17 fev. 2008.
} 
Outros, recorrendo a razões históricas como a ligação de Moçambique a Portugal, desde o processo de colonização até a independência dos moçambicanos, defendiam a pertinência não só da integração do país na CPLP como também do Acordo Ortográfico. Uma atitude conciliadora reflecte-se no hibridismo por que o país optou: Moçambique pertence às duas comunidades - a britânica e a dos países falantes de Português. Contudo, de lá a esta parte, o Acordo ficou esquecido, aliás, Moçambique ainda não o ratificou.

Mas a questão que se coloca é: quando é que Moçambique vai ratificar o Acordo? Ratificando-o, de quanto tempo precisará para fazer a substituição dos livros escolares em uso nas escolas e nos programas de alfabetização de adultos? É que aplicar o Acordo Ortográfico não é tão simples assim como pode parecer. Isto é: ratificar o Acordo só por ratificar, não pensando, portanto, nas implicações que poderão advir disso no país, sobretudo na área de ensino, poderá ser um gesto vazio de sentido.

O Brasil já ratificou o Acordo e como está na vanguarda na produção e edição de livros escolares pode já ter conformado os livros ao espírito do Acordo. E Moçambique? Moçambique recebe livros, principalmente, de editoras portuguesas. Ao que se sabe, Portugal ainda não ratificou o Acordo também. Estará Moçambique à espera de Portugal ou vai ratificar o Acordo independentemente de Portugal o fazer? E aqui não quero de forma alguma me referir a interesses comerciais sobrepostos(?) ao Acordo Ortográfico como alguns articulistas profetizam, chegando a relacionar o facto de Portugal não ter ainda ratificado o Acordo com o receio de perder a clientela africana a favor do Brasil, que é mais agressivo na produção e edição de livros. Se isso é verdade ou não, só as editoras dos dois países o poderão dizer.

Contudo, a questão dos materiais de ensino, sobretudo o livro escolar, é bastante sensível em Moçambique. Se no ensino primário do $1^{\circ}$ grau o livro é de distribuição gratuita, nem sempre chegando para todos os alunos atempadamente, embora se deva reconhecer que nos últimos tempos a situa- 
ção melhorou significativamente, o mesmo já não se pode dizer em relação aos livros ou manuais para os alfabetizandos adultos. Rareiam para os $1^{\circ} \mathrm{e}$ $2^{\circ}$ anos e não existem sequer para o $3^{\circ}$, o que requer muita criatividade da parte dos alfabetizadores.

No primeiro caso, acredito, os materiais poderão facilmente chegar às crianças já com a nova grafia, bastando que as editoras que fornecem livros escolares a Moçambique (portuguesas na maioria) actualizem esses materiais. Mas poderiam as editoras portuguesas produzir os materiais conformados ao Acordo Ortográfico sem que Portugal ratificasse o Acordo? Isto no caso de Moçambique se adiantar a Portugal, claro. Em quanto tempo se faria a substituição dos materiais?

Já no segundo caso, partindo do princípio que a área dos materiais (livros e manuais escolares) é de grande fragilidade em Moçambique, a nova grafia chegaria tarde aos alfabetizandos adultos, o que criaria muitos embaraços aos alfabetizadores, os quais teriam de explicar que determinadas palavras constantes dos poucos manuais de alfabetização têm uma grafia nova, diferente da que apresentam nesses manuais.

Naturalmente que a adopção da nova grafia por Moçambique iria implicar alguns sacrifícios por parte dos que já escrevem em Língua Portuguesa. E sem querer ser conservador, iria trazer momentos de alguma hesitação, e até certa confusão, passar a escrever, por exemplo, direcção e baptismo sem as consoantes mudas (c e p respectivamente), passar a não acentuar palavras graves com o ditongo oi tónico como, por exemplo, em heróico e bóia, e passar a redigir certas palavras sem o hífen. Isto só para referir algumas das principais alterações que o Acordo Ortográfico irá introduzir em Portugal e nos países africanos. Os que entrariam para o mundo da escrita na era da nova grafia, poderiam não passar por esse sacrifício desde que aprendessem a escrever já na nova moda e, sobretudo, com os materiais já actualizados. 
Se Moçambique quiser aplicar o Acordo Ortográfico deve antes de tudo reunir condições para que o Acordo não passe de letra morta: garantir que os que ainda vão entrar para o mundo da escrita tenham livros que possam servir de modelo.

\section{Considerações finais}

No Brasil pelo menos $40 \%$ da população possui pouco domínio da leitura e da escrita e desde o período colonial — passando pelo imperial até os dias de hoje, a distribuição de bens culturais tem sido desigual. Nem o Decreto n. 981 - Reforma Benjamin Constant; a Lei Rocha Vaz ou Reforma João Alves de 1925; o Decreto Lei 8.529 de 1946, que trata do ensino supletivo; nem as últimas Leis de Diretrizes e Bases (de 1961, 1967, 1971 e 1996) foram capazes de resolver a problemática da exclusão de milhões de brasileiros dos bancos escolares e do fracasso vivenciado por estas pessoas.

Em Moçambique, com cerca de 52 por cento de analfabetismo, com todos os problemas que há na provisão do ensino básico tanto a crianças quanto a adultos, não me parece neste momento que a escrita da palavra director, com ou sem c, faça diferença. Até porque uma das apostas das instâncias educacionais é consolidar o uso das outras línguas nacionais (na maioria são da família Bantu) no processo de ensino-aprendizagem, sobretudo nos programas de alfabetização de adultos assim como no ensino primário para crianças, uma vez que se acredita que o ensino na língua materna traz melhores resultados do que quando é numa segunda língua, devendo-se, isso sim, fazer uma transição gradativa para o Português, no caso vertente. Na verdade, num país com mais de vinte línguas Bantu, só uma minoria tem o Português como língua materna. Isso implica que no processo de ensinoaprendizagem se tenha que ensinar simultaneamente a falar a língua portuguesa e os conteúdos dos programas. Uma missão difícil! Significa que para muitas crianças e muitos adultos o ensino em língua portuguesa, sobretudo 
nas zonas rurais, continua a ser uma prática que exclui esses educandos do processo de ensino-aprendizagem por não poderem compreender nem falar a língua portuguesa. Acaba sendo uma opressão estudar nessas circunstâncias. Não seria mais importante, neste momento, prestar maior atenção às línguas nacionais, conhecidas as vantagens que há em ensinar na língua materna? Tendo em vista esta situação, consideramos que há muito trabalho a ser realizado para a construção e solidificação do mundo lusófono e não será por meio de decretos impostos, conforme apresentamos ao longo deste artigo, que a dignidade será construída nas antigas colônias portuguesas.

Tal posicionamento vai ao encontro do trabalho de alfabetização proposto por Paulo Freire (1987) no Brasil e em outros países, em território africano. Freire aboliu o formato convencional das salas de aula e, em círculos, realizava junto com seus alunos conversas, grupos de estudo, conferências, grupos de ação, fóruns, dentre outras atividades, que tinham como base o diálogo. Partia das palavras usadas por seus educandos (universo vocabular) e assim podia definir os temas geradores, que seriam o motivo do encontro cultural, com a língua e com a realidade. Neste sentido, a riqueza da língua portuguesa era estudada - em seus aspectos fonêmicos e fonéticos, aliados ao teor pragmático das palavras frente à realidade dos sujeitos envolvidos no processo de alfabetização. Na obra escrita com Guimarães, $A$ África Ensinando a Gente, Freire (1987) faz algumas colocações extremamente claras e humildes acerca das dificuldades e obstáculos enfrentados no momento de colaborar com os países africanos, ex-colônias portuguesas, e da impossibilidade da real implantação da reforma ortográfica.

Há ainda que destacar que esta reforma está inserida em um contexto social "globalizado", em que TUDO se transforma em mercadoria. Nesta direção e conforme Boaventura S. Santos (2005), o Capitalismo promove a mercadorização da educação, das escolas e de tudo que se relacione a ela. Temos um cotidiano cada vez mais mercantilizado, destruindo, portanto, as possibilidades de o trabalho e da escolarização serem um fator de inclusão 
social, já que os processos de exploração atingem o máximo de virulência e conflito, com o apoio das instituições educacionais. Esta lógica atinge, sobremaneira, aqueles que detêm menos capital, seja cultural, social ou material. Desta forma, infelizmente, como o próprio professor português nos diz, um caminho para o respeito universal, pela dignidade humana, está cada vez mais utópico.

Há que se ressaltar também que Mary Kato (1986) pôde afirmar que o Brasil é ainda uma "nação de real premazia do oral" (p. 39). Como a linguagem oral abriga subsistemas paralelos não previstos nas normas prescritivas da gramática, a "avalanche do uso oral ao lado do uso relativamente insignificante da escrita pode fazer com que, a longo prazo, as formas do oral venham a afetar as formas da escrita" (p. 39). Ela previu que no Brasil a força da oralidade marca a escrita, ao contrário das sociedades letradas, em que a fala simula a escrita. Ou seja, mesmo os falantes letrados revelam a primazia do oral, pois preferem procurar informação oral em vez de: consultar um guia, o manual, as leis e regimentos, uma enciclopédia, livros técnicos, etc. Dito de outro modo, qual é, de fato, a possibilidade de uma reforma ortográfica na Língua Portuguesa ter importância? Ou, nas palavras de Freire (1987), ser libertadora?

Há algo, porém, a considerar nesta descoberta, que está diretamente ligado à pedagogia libertadora. É que, quase sempre, num primeiro momento deste descobrimento, os oprimidos, em vez de buscar a libertação na luta e por ela, tendem a ser opressores também, ou subopressores. A estrutura de seu pensar se encontra condicionada pela contradição vivida na situação concreta, existencial, em que se formam. O seu ideal é, realmente, ser "humano", mas, para eles, ser "humano", na contradição em que sempre estiveram e cuja superação não lhes está clara, é ser opressor. Estes são o seu testemunho de humanidade.

O "homem novo", em tal caso, para os oprimidos, não é o homem a nascer da superação da contradição, com a transformação da velha situação 
concreta opressora, que cede lugar a uma nova, de libertação. Para eles, o novo homem são eles mesmos, tornando-se opressores de outros. A sua aderência ao opressor não lhes possibilita a consciência de si como pessoa, nem a consciência, nem a de classe oprimida (FREIRE, 1987, p. 32-33).

\section{Referências bibliográficas}

COSTA, J. R. (1988). Os Descobrimentos Portugueses: Pedro Álvares Cabral e o Brasil. São Paulo: Conselho da Comunidade Portuguesa do Estado de São Paulo, Editora Grupo Pão de Açúcar.

FREIRE, Paulo (1987). Pedagogia do oprimido. Rio de Janeiro: Paz e Terra.

; GUIMARÃES, Sérgio (2002). A África ensinando a gente. São Paulo: Paz e Terra.

KATO, Mary (1986). No mundo da escrita: uma perspectiva psicolinguística. São Paulo: Ática.

NOVO DICIONÁRIO DE LÍNGUA PORTUGUESA - Conforme Acordo Ortográfico (2008). Lisboa: Texto Editores.

POTT, Paula et al (2008). Atual - O Novo Acordo Ortográfico: o que vai mudar na grafia do português. Lisboa: Texto Editores.

SANTOS, Boaventura de Sousa (1999). Pela mão de Alice: o social e o político na pós-modernidade. São Paulo: Cortez. 


\section{AUTORES}

\section{Domingos Carlos BUQUE}

Docente da Faculdade de Educação da Universidade Eduardo Mondlane, Maputo, Moçambique.

E-mail: domingos.buque@uem.mz

\section{Luís Miguel CARDOSO}

Docente da Escola Superior de Educação de Viseu.

E-mail: 1mcardoso@esev.ipv.pt

\section{Maria de Jesus FONSECA}

Professora Adjunta da Escola Superior de Educação de Viseu.

E-mail: mjesus@esev.ipv.pt

\section{Nilce da SILVA}

Docente da Faculdade de Educação da Universidade de São Paulo, Brasil. E-mail: nilce@usp.br

Recebido em junho de 2008, aprovado em junho de 208.

\section{Como citar este artigo:}

BUQUE, Domingos Carlos et al. Alguns apontamentos sobre o Acordo Ortográfico: três olhares lusófonos - Brasil, Moçambique e Portugal. Revista ACOALFAplp: Acolhendo a Alfabetização nos Países de Língua portuguesa, São Paulo, ano 3, n. 5, 2008. Disponível em: <http://www.acoalfaplp.net>. Publicado em: setembro 2008. 